\title{
Sex and gender disparity in pathology, disability, referral pattern, and wait time for surgery in workers with shoulder injury
}

Helen Razmjou ${ }^{1,2,3^{*}}$ (D), Sandra Lincoln ${ }^{1,2}$, lona Macritchie ${ }^{4}$, Robin R. Richards ${ }^{5,6}$, Danielle Medeiros ${ }^{1}$ and Amr Elmaraghy ${ }^{5,6,7}$

\begin{abstract}
Background: The role of sex as an important biological determinant of vulnerability to sustaining injury and gender as a social determinate of access to resources, referral for medical care and perceived disability remains conflicted in injured workers. The purpose of this study was to examine sex and gender disparity following a compensable work-related shoulder injury.

Methods: This study involved cross-sectional analyses of data of two independent samples of workers with shoulder injury. Measures of disability and pain were the Quick Disabilities of the Arm, Shoulder and Hand (QuickDASH) and Numerical Pain Rating Scale (NPRS) for patients seen at an Early Shoulder Physician Assessment (ESPA) program and the American Shoulder and Elbow Surgeons (ASES) assessment form and Visual Analogue Scale (VAS) for the sample who underwent surgery.

Results: The files of 1000 (443 females, 557 men) consecutive patients seen at an ESPA program and 150 (44 females, and 106 men) consecutive patients who underwent rotator cuff surgery (repair or decompression) were reviewed. Significant gender disparity was observed in the referral pattern of injured workers seen at the ESPA program who were referred for surgical consultation ( $22 \mathrm{vs} .78 \%$ for females and males respectively, $p<0.0001$ ). The independent rotator cuff surgical group had a similar gender discrepancy ( $29 \%$ vs. $71 \%, p<0.0001$ ). The timeframe from injury to surgery was longer in women in the surgical group $(p=0.01)$. As well, women waited longer from the date of consent to date of surgery $(p=0.04)$. Women had higher incidence of repetitive injuries $(p=0.01)$ with men reporting higher incidence of falls $(p=0.01)$. Women seen at the ESPA program were more disabled than men $(p=0.02)$. Women in both samples had a higher rate of medication consumption than men $(p=0.01$ to $<0.0001)$. Men seen at the ESPA program had a higher prevalence of full thickness rotator cuff tears $(p<0.0001)$ and labral pathology $(p=0.01)$. However, these pathologies did not explain gender disparity in the subsample of ESPA who were referred for surgical consultation or those who had surgery.
\end{abstract}

Conclusions: Sex and gender disparity exists in workers with shoulder injuries and is evident in the mechanism of injury, perceived disability, medication consumption, referral pattern, and wait time for surgery.

Keywords: Sex, Gender disparity, Injured workers, Shoulder

\footnotetext{
* Correspondence: helen.razmjou@sunnybrook.ca

${ }^{1}$ Holland Orthopaedic \& Arthritic Centre, Sunnybrook Health Sciences Centre,

Toronto, Canada

${ }^{2}$ Department of Physical Therapy, Faculty of Medicine, University of Toronto,

Toronto, Canada

Full list of author information is available at the end of the article
}

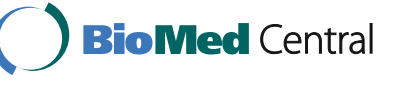

(c) 2016 The Author(s). Open Access This article is distributed under the terms of the Creative Commons Attribution 4.0 International License (http://creativecommons.org/licenses/by/4.0/, which permits unrestricted use, distribution, and reproduction in any medium, provided you give appropriate credit to the original author(s) and the source, provide a link to the Creative Commons license, and indicate if changes were made. The Creative Commons Public Domain Dedication waiver (http://creativecommons.org/publicdomain/zero/1.0/) applies to the data made available in this article, unless otherwise stated. 


\section{Background}

Rotator cuff injuries are known to be the most common source of disability of the work related shoulder conditions $[1,2]$ imposing a burden on health care and workers compensation systems [3-5]. Recent systematic reviews have shown that injured workers with shoulder conditions consistently report poorer outcomes than patients without work-related injuries [6,7] and compensated shoulder injuries are associated with higher levels of dissatisfaction and disability with longer time frames to return to full activities or gainful employment following surgery [8-15].

As noted, the negative impact of compensated shoulder injuries is a well-known fact. However, role of "sex" as a biological predictor of sustaining an injury or developing pathology and "gender" as a psychosocial determinant of access to resources, being referred for medical care or perceived disability in the injured workers have not been well examined.

Biological differences in anatomy, hormones, aerobic capacity and strength [16-19] may increase women's vulnerability in the workplace environment and increase the risk of sustaining certain pathologies. As well, biological differences in neuromuscular control system are reported to contribute to a higher rate of musculoskeletal disorders in women [20]. Gender-related differences in psychological and economic factors $[20,21]$ and clinicians' bias toward prioritizing male referrals for specialized medical consultation [22-24] may also affect the quality of care provided to women.

Most of the information on workers with shoulder injuries comes from studies with a small sample of injured workers within a larger group of patients. In one study that has examined the association between gender and an active compensated shoulder claim, the subsample of injured women reported less satisfaction with surgery than women without a work-related injury [25]. In other studies, women reported more post-operative pain than their male counterparts [12] and reported higher inability to perform certain shoulder tasks [11]. However, considering that these studies used a subsample of injured workers, these findings may not necessarily be applicable to the injured worker population when studied in isolation. Using samples that have both compensable and non-compensable injuries may confound the analysis of sex and gender disparity due to the complex interplay of biological, cultural and political factors that exist in the factor of disability and the binominal factor of man/women. Sex and gender disparity in injured workers would be more accurately explored if the confounding factor of a compensable injury is accounted for by including only injured workers.

The purposes of this study were to examine 1) the observed differences between men and women in age, mechanism of injury, pathology, perceived disability and medication consumption which were affected by both biological and non-biological factors and 2) gender disparity in the referral pattern for recommending surgery and wait time to have surgery following a compensable shoulder injury.

\section{Methods \\ Design}

This study involved cross-sectional data analyses of two independent samples of workers with an active compensable shoulder injury who were referred for either an expedited assessment or surgery.

\section{Patient population}

The first sample comprised of consecutive injured workers seen at an Early Shoulder Physician Assessment (ESPA) program, whose data were examined retrospectively (ESPA group). They were workers with shoulder injuries who had not progressed in their recovery or return to work (RTW) plan within 16 weeks of the injury or reoccurrence and had a variety of diagnoses including impingement syndrome, rotator cuff tendinitis, partial or full thickness rotator cuff tear, adhesive capsulitis, or labral pathologies. Patients were seen by an orthopedic surgeon and a physical therapist. Recommendations for further treatment such as conservative or surgical management were documented. Data of the subsample of ESPA group who were referred for surgical consultation were examined separately. Approval for using the retrospective data of this sample was obtained from the Research Ethics Board of the Sunnybrook Health Sciences Centre.

The second sample involved an independent sample of consecutive injured workers who had an expedited rotator cuff related surgery and had participated in a prospective study (surgical group). The inclusion criteria for this sample included an active work-related shoulder injury, age $\geq 18$ years, diagnosis of tendonitis, partial or full-thickness rotator cuff tear confirmed by MRI or US. Patients with evidence of advanced osteoarthritis of the glenohumeral joint, inflammatory arthropathy, concurrent pathology of Superior Labral Anterior and Posterior (SLAP) lesions or Bankart lesions that required a repair were excluded. Arthroscopic rotator cuff decompression (acromioplasty, lateral resection of clavicle) was performed for osseous impingement, acromioclavicular arthritis or partial thickness rotator cuff tears where arthroscopic repair was conducted for full thickness rotator cuff tears. Low grade partial tears of biceps $(<50 \%)$ were debrided. Biceps tenodesis or tenotomy was conducted for high-grade tears of the tendon as appropriate. The size of rotator cuff tear (largest dimension) was categorized as small $<1 \mathrm{~cm}$, moderate $(1-3 \mathrm{~cm}$.), large (>3-5 cm.), and massive (>5 cm.) [26]. All patients in the surgical group had provided consent to participate in 
research and the study was approved by the Research Ethics Board of the Sunnybrook Health Sciences Centre.

\section{Outcome measures}

Patient-related outcome measures which were completed at the time of assessment in the ESPA group included the numeric pain rating scale (NPRS), and the Quick Disabilities of the Arm, Shoulder and Hand (QuickDASH) [27].

Outcome measures in the surgical group included the Visual Analogue Scale (VAS) [28] and the American Shoulder and Elbow Surgeons (ASES) assessment form [29].

The NPRS and VAS use a 0 to 10 scale with 0 being no pain and 10 being the worst imaginable pain and are valid for clinical use [30, 31]. Both the QuickDASH and ASES measures have established validity and reliability in patients with shoulder complaints [27, 32-34] and have shown high correlation with one another [25, 35].

\section{Referral pattern and wait time}

The referral pattern was examined by exploring differences in the proportion of men and women in each sample. Wait time reflected time between date of injury and date of assessment in the ESPA group and those who were referred for surgical consultation. In the independent surgical group, wait time reflected time between date of injury and date of surgery. In addition, the time period between the date patient consented to surgery and date of actual surgery was examined in the surgical group.

\section{Statistical analysis}

Descriptive statistics were conducted in each sample to examine potential sex and gender differences in demographics (e.g. age, medication use, mechanism of injury, type of pathology/surgery), pain (NPRS and VAS) and disability (as measured by QuickDASH or ASES). The Chi square $\left(\chi^{2}\right)$ tests examined proportions between men and women. To examine the goodness of fit in $2 \times 2$ contingency tables and magnitude of meaningful difference between the number of men and women in each group, phi coefficients were calculated and Cohen's effect size criteria [36] were used to interpret the effect sizes $(0.1=$ small, $0.3=$ medium and $0.5=$ large $)$. Categorical data were examined by Chi square and Fisher's Exact tests as appropriate and continuous data were examined by independent student t-tests or Wilcoxon two sample test depending on normality of data.

\section{Results}

\section{ESPA group}

Files of 1000 consecutive patients were reviewed retrospectively. The sample included 443 females (44\%) and
557 men (56\%) with the mean age of 49 (11), range $18-77$ years $\left(\chi^{2} 12.99, p=0.0003\right.$, Phi coefficient $=0.11$, $95 \% \mathrm{CI}=0.07-0.16$, Effect size $=$ small $)$.

\section{ESPA subgroup}

Of 1000 patients seen at the ESPA, 169 (17 \%) patients were referred for surgical consultation after the first assessment. This subsample included 38/169 (22\%) women and 131/169 (78 \%) men. There was a statistically significant difference in the proportion of men and women referred for surgical consultation $\left(\chi^{2}=51.17, p<0.0001\right.$, Phi coefficient $=0.55,95 \% \mathrm{CI}=0.46-0.64$, Effect size $=$ large).

\section{Surgical group with rotator cuff pathology}

Pre-operative data of 150 consecutive patients who had participated in an independent prospective study were reviewed. This sample included 44 females $(29 \%)$ and 106 men (71\%), mean age 52, range 27-75 years $\left(\chi^{2}=25.63\right.$, $p<0.0001$, Phi coefficient $=0.41,95 \% \mathrm{CI}=0.31-0.51$, Effect size $=$ medium $)$.

\section{Sex/gender related differences}

Tables 1, 2 and 3 show the characteristics of the groups. Females' age was comparable to males in all three samples.

\section{Mechanism of Injury}

In the ESPA group, females had higher incidence of repetitive injuries $(p=0.01)$ with men reporting higher incidence of falls $(p=0.01)$ (Table 1$)$. However, no differences were observed in mechanism of injury in those who were referred for surgical consultation (Table 2) or those who had a rotator cuff related surgery (Table 3).

\section{Prevalence of pathology}

In the ESPA group who had a variety of shoulder pathologies, labral tears occurred exclusively in men and men also had a statistically significant higher prevalence of full-thickness rotator cuff tears (Table 1). Prevalence of rotator cuff impingement syndrome, biceps pathology, adhesive capsulitis, partial-thickness rotator cuff tears, and glenohumeral instability was similar between men and women.

Full-thickness rotator cuff tear was the prominent diagnosis $(81 / 169=48 \%)$ of the patients referred for surgery, and although there was a trend towards a higher prevalence of these tears in men ( $\mathrm{F}: 39 \%$ vs. M: $50 \%$ ), the difference did not reach statistical significance. Prevalence of all other pathologies was also comparable between men and women referred for surgery (Table 2).

Similarly, in the surgical group who had surgery for rotator cuff pathology, no differences were observed in the frequency of rotator cuff repair, acromioplasty, distal clavicle excision or biceps tenotomy/tenodesis (Table 3). 
Table $1 \mathrm{Sex} / \mathrm{Gender}$ differences in the ESPA group $(N=1000)$

\begin{tabular}{|c|c|c|c|}
\hline $\begin{array}{l}\text { Variables } \\
\text { (Mean, SD)/(N/\%) }\end{array}$ & Women (\%) & Men (\%) & Statistics $P$ values \\
\hline$\overline{\text { Age }}$ & $49(11)$ & $49(11)$ & ttest $=0.65, p=0.51$ \\
\hline Referral pattern & $443(44 \%)$ & $557(56 \%)$ & $\begin{array}{l}x^{2}=12.99, p=0.0003 \\
\text { Phi coefficient }=0.11 \\
95 \% \mathrm{Cl}=0.07-0.16 \\
\text { Effect size }=\text { Small }\end{array}$ \\
\hline $\begin{array}{l}\text { Wait time to } \\
\text { assessment (months) }\end{array}$ & $2.68(0.98)$ & $2.63(0.80)$ & ttest $=0.84, p=0.40$ \\
\hline \multicolumn{4}{|l|}{ Affected Side } \\
\hline $\begin{array}{ll}\cdot & \text { Right } \\
\cdot & \text { Left } \\
\cdot & \text { Bilateral }\end{array}$ & $\begin{array}{l}269(61 \%) \\
162(37 \%) \\
12(3 \%)\end{array}$ & $\begin{array}{l}321(58 \%) \\
225(40 \%) \\
11(2 \%)\end{array}$ & $x^{2}=1.9, p=0.38$ \\
\hline \multicolumn{4}{|l|}{ Mechanism of injury } \\
\hline $\begin{array}{ll}\text { - } & \text { Repetitive activities } \\
\text { - } & \text { Fall } \\
\text { - Traumatic } \\
\text { - } & \text { Push/pull }\end{array}$ & $\begin{array}{l}69(16 \%) \\
54(12 \%) \\
47(11 \%) \\
175(40 \%)\end{array}$ & $\begin{array}{l}58(10 \%) \\
100(18 \%) \\
53(10 \%) \\
237(43 \%)\end{array}$ & $\begin{array}{l}x^{2}=5.93, p=0.01 \\
x_{2}^{2}=6.29, p=0.01 \\
x^{2}=0.32, p=0.57 \\
x^{2}=0.94, p=0.33\end{array}$ \\
\hline \multicolumn{4}{|l|}{ Medication use } \\
\hline $\begin{array}{ll}\text { - } & \text { Non-narcotic } \\
& \text { analgesics } \\
\text { - } & \text { Anti-inflammatory } \\
\text { - } & \text { Muscle relaxants }\end{array}$ & $\begin{array}{l}213(48 \%) \\
258(58 \%) \\
42(9 \%)\end{array}$ & $\begin{array}{l}229(41 \%) \\
237(42 \%) \\
19(3 \%)\end{array}$ & $\begin{array}{l}x^{2}=4.85, p=0.03 \\
x^{2}=24.29, p<0.0001 \\
x^{2}=15.87, p<0.0001\end{array}$ \\
\hline \multicolumn{4}{|l|}{ Type of pathology } \\
\hline $\begin{array}{ll}\text { - } & \text { FTRCT } \\
\text { - } & \text { PTRCT } \\
\text { - } & \text { Impingement } \\
& \text { syndrome } \\
\text { - } & \text { Biceps pathology } \\
\text { - } & \text { Adhesive capsulitis } \\
\text { - } & \text { Labral pathology } \\
\text { - } & \text { Instability }\end{array}$ & $\begin{array}{l}28(6 \%) \\
95(21 \%) \\
231(52 \%) \\
172(39 \%) \\
35(8 \%) \\
0(0 \%) \\
8(2 \%)\end{array}$ & $\begin{array}{l}93(17 \%) \\
128(23 \%) \\
289(52 \%) \\
220(39 \%) \\
43(8 \%) \\
10(2 \%) \\
14(3 \%)\end{array}$ & $\begin{array}{l}X^{2}=24.97, p<0.0001 \\
\mathrm{RR}=0.38^{\mathrm{a}}, 0.25-0.57 \\
X^{2}=0.34, p=0.56 \\
X^{2}=0.006, p=0.93 \\
X^{2}=0.05, p=0.82 \\
X^{2}=0.02, p=0.91 \\
\text { FET }=0.01, p=0.01 \\
x^{2}=0.57, p=0.45\end{array}$ \\
\hline
\end{tabular}

FET Fisher's Exact Test, $x^{2}=$ Chi square

${ }^{\text {a }} \mathrm{A}$ risk ratio of 0.38 is expressed as women having decreased risk of presenting with FTRCT by $62 \%: 100 \times(1-0.38) \%$

However, among those who had a rotator cuff repair, men had a slightly higher incidence of larger tears than women. Women had a higher rate of small $(<1 \mathrm{~cm}$.) (65\% vs. $45 \%)$ and moderate $(1-3 \mathrm{~cm}$.) sized tears (18\% vs.10\%) and men had a higher rate of large or massive tears ( 3 to $>5 \mathrm{~cm}$.) ( $40 \%$ vs. $16 \%, p=0.049)$.

\section{Perceived pain and disability}

No statistically significant differences were observed between men and women seen in the ESPA with respect to pain as measured by the NPRS. However, women of the full sample and those who were referred for surgical consultation reported more disability as measured by the QuickDASH (Table 4). In the surgical group, there were no statistically significant differences between men and women with respect to the pre-operative ASES or VAS (Table 4).

\section{Medication utilization}

In the ESPA group, females took more non-narcotic analgesics, muscle relaxants, and anti-inflammatory medications.
Table 2 Sex/Gender differences in the ESPA subgroup referred for surgical consultation $(N=169)$

\begin{tabular}{|c|c|c|c|}
\hline $\begin{array}{l}\text { Variables } \\
\text { (Mean, SD)/(N/\%) }\end{array}$ & Women (\%) & Men (\%) & Statistics $P$ values \\
\hline Age & $54(10)$ & $53(10)$ & ttest $=0.58, p=0.56$ \\
\hline Referral pattern & $38(22 \%)$ & $131(78 \%)$ & $\begin{array}{l}x^{2}=51.17, p<0.0001 \\
\text { Phi coefficient }=0.55 \\
95 \% \mathrm{Cl}=0.46-0.64 \\
\text { Effect size = Large }\end{array}$ \\
\hline $\begin{array}{l}\text { Wait time to } \\
\text { assessment (months) }\end{array}$ & $2.83(0.98)$ & $2.46(0.80)$ & ttest $=1.04, p=0.30$ \\
\hline \multicolumn{4}{|l|}{ Affected Side } \\
\hline $\begin{array}{ll}\text { - } & \text { Right } \\
\text { - } & \text { Left }\end{array}$ & $\begin{array}{l}21 \\
17\end{array}$ & $\begin{array}{l}84 \\
47\end{array}$ & $x^{2}=0.98, p=0.32$ \\
\hline \multicolumn{4}{|l|}{ Mechanism of injury } \\
\hline $\begin{array}{ll}\text { - } & \text { Repetitive } \\
& \text { activities } \\
\text { - } & \text { Fall } \\
\text { - } & \text { Traumatic } \\
\text { - } & \text { Push/pull }\end{array}$ & $\begin{array}{l}5(13 \%) \\
54(12 \%) \\
3(8 \%) \\
13(34 \%)\end{array}$ & $\begin{array}{l}7(5 \%) \\
100(18 \%) \\
16(12 \%) \\
50(38 \%)\end{array}$ & $\begin{array}{l}x^{2}=2.70, p=0.10 \\
x_{2}^{2}=0.11, p=0.73 \\
x_{2}^{2}=0.55, p=0.46 \\
x^{2}=0.20, p=0.66\end{array}$ \\
\hline \multicolumn{4}{|l|}{ Medication use } \\
\hline $\begin{array}{ll}\text { - } & \text { Non-narcotic } \\
& \text { analgesics } \\
\text { - } & \text { Anti-inflammatory } \\
\text { - } & \text { Muscle relaxants }\end{array}$ & $\begin{array}{l}20(53 \%) \\
(58 \%) \\
0(0 \%)\end{array}$ & $\begin{array}{l}57(44 \%) \\
237(42 \%) \\
3(2 \%)\end{array}$ & $\begin{array}{l}X^{2}=0.98, p=0.32 \\
X^{2}=0.01, p=0.92 \\
\text { FET }=0.46, p=1.80\end{array}$ \\
\hline \multicolumn{4}{|l|}{ Type of pathology } \\
\hline $\begin{array}{ll}\text { - } & \text { FTRCT } \\
\text { - } & \text { PTRCT } \\
\text { - } & \text { Impingement } \\
& \text { syndrome } \\
\text { - } & \text { Biceps pathology } \\
\text { - } & \text { Labral pathology } \\
\text { - } & \text { Instability }\end{array}$ & $\begin{array}{l}15(39 \%) \\
13(34 \%) \\
9(24 \%) \\
14(37 \%) \\
0(0 \%) \\
3(2 \%)\end{array}$ & $\begin{array}{l}66(50 \%) \\
30(23 \%) \\
19(15 \%) \\
49(37 \%) \\
4(40 \%) \\
5(3 \%)\end{array}$ & $\begin{array}{l}X^{2}=1.40, p=0.24 \\
X^{2}=1.98, p=0.16 \\
X^{2}=1.79, p=0.18 \\
X^{2}=0.004, p=0.94 \\
\text { FET }=1.18, p=0.28 \\
\text { FET }=0.18, p=0.38\end{array}$ \\
\hline
\end{tabular}

Similarly, in the surgical group, females took more non-narcotic analgesics, and anti-inflammatory medications (Tables 1, 2 and 3).

\section{Gender-related differences Referral pattern}

As noted earlier, there was a small effect size difference between men and women of the ESPA group who were referred for assessment. However, a large difference was observed between men and women referred for surgical consultation of whom only $38(22 \%)$ were females with 131(78 \%) being males, indicating significant gender disparity. The independent rotator cuff surgical group had a similar discrepancy between women and men (F: 29 vs. M: $71 \%$ ) with a medium effect size difference.

\section{Wait time}

No statistically significant time differences were observed between men and women to see the specialist in the ESPA group (Table 1) or those who were referred for surgical consultation (Table 2). However, the timeframe from injury 
Table 3 Sex/Gender differences in the independent rotator cuff surgical group

\begin{tabular}{llll}
\hline $\begin{array}{l}\text { Variables } \\
\text { (Mean, SD)/(N/\%) }\end{array}$ & Women (\%) & Men (\%) & Statistics $P$ values \\
\hline Age & $51(10)$ & $52(8)$ & ttest $=0.43, p=0.66$ \\
Referral pattern (N,\%) & $44(29 \%)$ & $106(71 \%)$ & $x^{2}=25.63, p<0.0001$ \\
& & & Phi coefficient $=0.41$, \\
& & $95 \% \mathrm{Cl}=0.31-0.51$ \\
& & Effect size $=$ Medium
\end{tabular}

Wait time

$\begin{array}{llll}\text { Wait time1 } & 20(13) & 14(12) & \text { Wilcoxon test }=2.61, \\ \text { wait time2 } & 95(50) & 77(41) & p=0.01 \\ & & \text { Wilcoxon test }=2.08, \\ & & p=0.04\end{array}$

Affected Side

- Right

- Left

- Bilateral

27 (61\%)

$14(32 \%)$

$51(48 \%)$

$44(42 \%)$

$\mathrm{FET}=0.01, p=0.36$

$3(7 \%)$

$11(10 \%)$

Side operated on

- Right

- Left

$57(73 \%)$

$21(27 \%)$

$48(59 \%)$

$34(41 \%)$

Mechanism of injury

- Insidious

- Repetitive activities

- Fall

- Traumatic

- Other

Pre-surgical medication

use

\begin{tabular}{|c|c|c|c|}
\hline $\begin{array}{ll}\text { - } & \text { Non-narcotic } \\
\text { analgesics } \\
\text { - } & \text { Anti-inflammatory } \\
\text { - } & \text { Narcotics }\end{array}$ & $\begin{array}{l}18(41 \%) \\
16(36 \%) \\
5(11 \%)\end{array}$ & $\begin{array}{l}25(24 \%) \\
17(16 \%) \\
9(8 \%)\end{array}$ & $\begin{array}{l}X^{2}=4.56, p=0.03 \\
X^{2}=7.49, p=0.01 \\
\mathrm{FET}=0.30, p=0.58\end{array}$ \\
\hline \multicolumn{4}{|l|}{ Type of surgery } \\
\hline $\begin{array}{ll}\text { - } & \text { RC repairs } \\
\text { - } & \text { Resection of } \\
& \text { clavicle } \\
\text { - } & \text { Acromioplasty } \\
\text { - } & \text { Biceps tenodesis } \\
\text { - } & \text { Biceps tenotomy } \\
\text { - } & \text { Debridement }\end{array}$ & $\begin{array}{l}19(43 \%) \\
9(20 \%) \\
41(93 \%) \\
2(5 \%) \\
3(7 \%) \\
13(30 \%)\end{array}$ & $\begin{array}{l}52(49 \%) \\
24(23 \%) \\
96(91 \%) \\
8(8 \%) \\
13(12 \%) \\
40(38 \%)\end{array}$ & $\begin{array}{l}X^{2}=0.83, p=0.36 \\
X^{2}=0.09, p=0.77 \\
X^{2}=0.27, p=0.60 \\
\text { FET }=0.24, p=0.72 \\
\text { FET }=0.15, p=0.40 \\
X^{2}=0.91, p=0.34\end{array}$ \\
\hline \multicolumn{4}{|l|}{$\begin{array}{l}\text { Tear size } \\
\text { in cuff repair group) }\end{array}$} \\
\hline $\begin{array}{l}\text { Small } \\
\text { Moderate } \\
\text { Large } \\
\text { Massive }\end{array}$ & $\begin{array}{l}4(21 \%) \\
11(58 \%) \\
3(16 \%) \\
1(5 \%)\end{array}$ & $\begin{array}{l}6(12 \%) \\
23(44 \%) \\
14(27 \%) \\
9(17 \%)\end{array}$ & $\mathrm{FET}=0.02, p=0.049$ \\
\hline
\end{tabular}

FET Fisher's Exact Test

$x^{2}=$ Chi square

Wait time1: Symptom duration (months)

Wait time2: Consent date to surgical date (days)

to surgery (symptom duration) was longer in women who underwent surgery (20 vs. 14 months, $p=0.01$ ). A similar gender disparity was observed in the wait-time to have surgery (date patient consented to surgery to the date of actual surgery) with women waiting 95 days vs. men waiting 77 days $(p=0.038)$.
Table 4 Disparity between men and women in perceived pain and disability

\begin{tabular}{llll}
\hline Variables (Min/Max) & $\begin{array}{l}\text { Women } \\
\text { Mean (SD) }\end{array}$ & $\begin{array}{l}\text { Men } \\
\text { Mean (SD) }\end{array}$ & Statistics $P$ values \\
\hline ESPA group & & & \\
NPRS $(0 / 10)$ & $5.9(2)$ & $5.7(2)$ & ttest $=1.42, p=0.15$
\end{tabular}

Quick DASH (0/100) 58(22) 54(33) ttest $=2.27, p=0.02$

ESPA subgroup referred

for surgical consultation

$\begin{array}{llll}\text { NPRS (0/10) } & 6.24(2) & 5.95(2) & \text { ttest }=0.70, p=0.40 \\ \text { Quick DASH (0/100) } & 65(21) & 58(19) & \text { ttest }=2.08, p=0.04\end{array}$

Independent Surgical

group

$\begin{array}{llll}\operatorname{VAS}(0 / 10) & 6.7(2) & 6.7(2) & \text { ttest }=0.2, p=0.81 \\ \text { ASES }(0 / 100) & 34(16) & 33(15) & \text { ttest }=0.39, p=0.70\end{array}$

ASES American Shoulder and Elbow Surgeons, ESPA Early Shoulder Physician Assessment, FET Fisher's Exact Test, Quick DASH Quick Disabilities of the Arm, Shoulder and Hand, NPRS Numeric Pain Rating Scale

\section{Discussion}

Biological differences in anatomy, strength, hormones, neuromuscular control, and musculoskeletal flexibility can have a negative impact on women's health. Similarly, gender differences in access to resources, inequalities for being referred for specialist assessment or surgery can have negative health consequences. Although these differences are reported in the general population, there is limited information on sex/gender disparity in injured workers with shoulder pathology. The present study used consecutive injured workers with an active shoulder compensation claim from two different programs designed to expedite assessment and surgical management and showed discrepancy between men and women in terms of mechanism of injury, pathology, medication use, being referred for surgery and waiting to have surgery.

\section{Mechanism of injury}

Previous research has shown that in the general population, men report more traumatic injuries than women, potentially due to their different life style and higher risk-taking behaviors [37-39]. In the present study, where all patients were injured workers, repetitive injuries were more prevalent in women in the ESPA group who were referred for an early assessment. Women more often occupy jobs that involve computer work, prolonged precision demands, awkward postures or repetitive activities [40-42]. In addition, they have less muscle strength and higher reaction time [43] which may explain the higher prevalence of these injuries in women. Men on the other hand had a higher rate of falls on the same level. Of fall injuries treated in Emergency departments, fractures and injuries among older women are reported to be higher than for older men [44]. 
Unfortunately, the literature on the incidence of falls in working-age women is limited. What is interesting is that despite the fact that women reported more repetitive injuries and men had a higher rate of falls in the ESPA group, these injuries did not differ in the sample of surgical candidates or those who required surgery.

\section{Prevalence and type of pathology}

The present study found that sex of the patient was correlated with the rotator cuff tear size with women having smaller rotator cuff tears than men. In one study [45] that examined 108 women and 171 men, younger women $(<55$ years of age) had a higher prevalence of small tears compared with their male counterparts. This difference was not statistically significant between older men and women. Considering, the overall women's smaller stature, older women potentially had more significant tears than men in the same age group. In a systematic review by $\mathrm{Oh}$ et al., [12] shoulder pain had a higher prevalence in older female patients of 70 to 79 years of age. An epidemiological study has also reported [46] that rotator cuff pathology is more common in women than in men (90 vs. 83 cases per 100,000 people-years in women and men respectively; $p<0.001$ ). The samples used in our study included traumatic rotator cuff tears in the younger working individuals which may explain the higher incidence of pathology in men.

Certain pathologies have a different prevalence in men and women as a result of anatomical differences [47-49] and a higher involvement of men in overhead sports. For example men are approximately three to four times more likely to suffer from neuropathy secondary to suprascapular nerve entrapment syndrome than females [50]. Lack of good epidemiologic studies on labral tears makes the interpretation of prevalence of SLAP tears difficult but some authors [51] have indicated a higher prevalence of this pathology in men, may be due to their involvement in contact and overhead sports activities.

\section{Sex-related role of hormones on tendon pathology}

There is a body of literature on the association between thyroid hormones and tendinopathy [52-58]. Thyroxine has an important role in collagen synthesis and matrix metabolism [59]. Hypothyroidism can cause accumulation of glycosaminoglycans (GAGs) in the extracellular matrix, leading to higher incidence of tendon calcification [58]. In a retrospective study of a large sample of patients $(N=441)$, Oliva et al. [54] reported that thyroid disease was more prevalent in females, independent of age. The prevalence was highest among women in the age group of 60-80 years (women:63 vs. men:23\%) [54] which shows the role of thyroid hormones on modifying and increasing the rate of age related or non-traumatic rotator cuff tear.
Heart et al. [60] have proposed that the higher prevalence of rotator cuff tears in women can be partly explained by hormonal variation in estrogens and thyroxin which may influence collagen and matrix metabolism at a structural and biochemical level [52]. Among co-morbidities, a higher presence of hormonerelated gynecologic diseases, autoimmune pathologies, hypothyroidism, rheumatoid arthritis and type 1 diabetes mellitus were found most frequently in women with calcifying tendinopathy $[61,62]$.

In the present study, the incidence of thyroid condition was not documented and could not be analyzed. It is of note that our sample involved younger women with traumatic pathologies which may reduce the influence of thyroid conditions on development of degenerative rotator cuff pathologies. Sex-related differential role of endocrine disorders that can lead to an early development of shoulder symptoms in women deserves further investigation and should not be underestimated. Future studies should investigate the role of thyroid problems in the development of rotator cuff disease in injured workers.

\section{Perceived pain and disability}

In the present study, a higher disability based on QuickDASH was reported in women in the ESPA group and the ESPA subgroup which is consistent with the available literature. Curry et al. [63] who examined 67 patients with rotator cuff tears undergoing operative and non-operative treatment reported higher disability in women based on the Shoulder Pain and Disability Index (SPADI). Similarly, Harris et al. [64] who reviewed 389 patients with symptomatic atraumatic rotator cuff tears reported the female sex as a negative predictor of ASES scores. Razmjou et al. reported that female candidates for rotator cuff surgery reported higher levels of disability despite similar or lower levels of pathology $[39,45]$. Interestingly, in the present study, women who were to undergo surgery did not necessarily perceive themselves as being more disabled than men based on the ASES. This may indicate that female injured workers may learn to adjust or adapt to their functional difficulty as they wait longer to have surgery. However, this discrepancy warrants further investigation.

\section{Medication use}

Women in both groups took more medication. The difference in perception of pain in women has been extensively documented [65-67]. Sex-related neuroanatomical and physiological differences may explain a variety of chronic pain syndromes that are vastly more pervasive in women than men. [68]. Gender related factors such as social conditioning, cultural upbringing, drug dependency traits, negative affect and other psychosocial factors do play a role on pain perception and medication use as well [69]. 
Acknowledging differences in use of medication in injured workers is critical in providing healthcare services that focus on improving pain and function. This may include facilitating and expediting women's care (conservative or surgical).

\section{Referral pattern}

The fairly similar percentage of men and women (58 VS. $43 \%)$ seen at the ESPA program reflected by the small effect size suggests a comparable rate of referral of male and female injured workers. According to Stats Canada [70] women in general are more likely to have a regular medical doctor than men ( $89 \%$ vs. $81 \%$ ). In 2009, the largest gender gap in this regard was in the 20-to-34 age group, in which $81 \%$ of women had a regular medical doctor versus only $67 \%$ of men. Partly reflecting the fact that women were more likely to have access to a regular medical doctor, they were also more likely than men to have consulted a doctor in 2009 (86 \% vs. $74 \%$ \%). In Ontario, Canada the access rate was $94 \%$ vs. $89 \%$ in women and men respectively. This may explain why females with injuries did not differ that significantly from their male counterpart in terms of seeing a specialist as even in the presence of potential bias from the family physician or nurse case managers, their tendency to seek more help has neutralized the potential differences.

However, the referral pattern of the surgical candidates of the same sample and the independent sample of rotator cuff pathology group indicates more gender disparity. We observed a large differential pattern of referral (large effect size of 0.55 ) between men and women who required surgical consultation (ESPA group). This discrepancy was less in magnitude (medium effect size of 0.41 ) in patients who actually had a rotator cuff-related surgery. In both groups who either needed surgical consultation or underwent surgery, the number of men was significantly higher despite similarity of pathology. Although a higher prevalence of full-thickness rotator cuff and labral tears was observed in men in the ESPA group, this did not explain the discrepancy in the referral pattern of those who needed surgical consultation or underwent surgery. Therefore, the discrepancy in the number of men and women in the surgical groups cannot be explained by higher incidence of pathology and appears to be related to non-biological factors. Our findings are consistent with the literature in general population which indicates that patient's gender has an impact on physician's decision to refer a patient for, or to perform certain musculoskeletal surgeries [22-24, 71, 72].

\section{Wait time differences for surgery}

The gender-related difference in wait time to surgery found in this study is consistent with previous studies. Gender disparity in use of health care services has been noted in the literature [73-76]. In addition, women's persistently social and dominant domestic role in the family dwelling may contribute to postponing their own priorities for the sake of other family members. The gender-specific roles may contribute to longer wait time to surgery $[37,38,77,78]$.

\section{Limitations}

The present study examined basic sex and gender differences in two samples of injured workers seen in a specialized academic institute and was limited to available data. In addition, our results may not be applicable to communitybased hospitals where access to specialists is more limited. Although, men and women used the same outcome measures in each sample, there was variability in type of subjective outcomes between two samples. However, these measures have shown high correlation with one another.

Studies that explore work-related gender disparity are influenced by complex political (job availability, pay equality), physical and mental occupational demands, cultural (care giving roles) and social factors (marital status, level of income, access to the health care system, and extent of family and social support). Given the complexity of these relationships, more comprehensive and gender-sensitive measures and analyses are required to capture all important aspects of sex and gender disparity and interaction. More research is needed to examine the differential role of hormones such as thyroxin on tendon pathology and healing.

\section{Conclusion}

Sex and gender disparity exists in workers with shoulder injuries and is evident in the mechanism of injury, perceived disability, medication consumption, referral pattern, and wait time for surgery. Understanding these differences may assist clinicians to customize their management based on the sex of the injured workers. Expedited surgical programs should aim at reducing these differences to assist with lowering the cost of disability in injured workers.

\section{Abbreviations \\ ASES: American shoulder and elbow surgeons; ESPA: Early shoulder physician assessment; FET: Fisher's exact test; MRI: Magnetic resonance imaging; NPRS: Numeric pain rating scale; Quick DASH: Quick disabilities of the arm, shoulder and hand; RTW: Return to work; SD: Standard deviation; US: Ultrasound}

\section{Acknowledgement}

Authors wish to thank Kamelia Rostami for her contribution to data entry of this study.

\section{Funding}

No external funding was obtained for this study.

Availability of data and materials

Data used in this study are part of a larger study which has not been completed and will not be shared. 


\section{Authors' contributions}

$A E(M D, F R C S C)$ posed the research questions and was involved in data analysis interpretation. HR (PT, PhD) supervised data collection, extraction and entry, performed data analysis and drafted the manuscript. SL (PT, MSC) was involved in clinical examination and data collection and presented an earlier version of the study at the 26th Congress of the ESSSE in Milan, Italy. IM (BHSC, MHSC, OT, CHE), RRR (MD, FRCSC) and DM (MSC., OT, HSC) were involved in program development. All authors were involved in critical revision of the important content of the manuscript and approved the final version of the article.

\section{Competing interests}

The authors declare that they have no competing interests.

\section{Consent for publication}

Not applicable.

\section{Ethics approval and consent to participate}

All patients in the surgical group had provided consent to participate in research. Approval for using the retrospective data of the ESPA sample and use of human subjects of the prospective study was obtained from the Research Ethics Board of the Sunnybrook Health Sciences Centre.

\section{Author details}

${ }^{1}$ Holland Orthopaedic \& Arthritic Centre, Sunnybrook Health Sciences Centre, Toronto, Canada. ${ }^{2}$ Department of Physical Therapy, Faculty of Medicine University of Toronto, Toronto, Canada. ${ }^{3}$ Sunnybrook Research Institute, Sunnybrook Health Sciences Centre, Toronto, Canada. ${ }^{4}$ Toronto Rehabilitation Institute, Lyndhurst Centre, Brain \& Spinal Cord Rehabilitation Program, Toronto, Canada. ${ }^{5}$ Division of Orthopedic Surgery, Department of Surgery, Sunnybrook Health Sciences Centre, Toronto, Canada. ${ }^{6}$ Department of Orthopedic Surgery, Faculty of Medicine, University of Toronto, Toronto, Canada. ${ }^{7}$ Department of Orthopaedic Surgery, St. Joseph's Health Centre, Toronto, Canada.

Received: 19 April 2016 Accepted: 14 September 2016 Published online: 21 September 2016

\section{References}

1. Largacha M, Parsons III IM, Campbell B, Titelman RM, Smith KL, Matsen III F. Deficits in shoulder function and general health associated with sixteen common shoulder diagnoses: a study of 2674 patients. J Shoulder Elbow Surg. 2006;15(1):30-9.

2. Zakaria D, Robertson J, MacDermid JC, Hartford K, Koval J. Estimating the population at risk for Ontario Workplace Safety and Insurance Board-covered injuries or diseases. Chronic Dis Can. 2002;23(1):17-21.

3. van den Heuvel SG, ljmker S, Blatter BM, de Korte EM. Loss of productivity due to neck/shoulder symptoms and hand/arm symptoms: results from the PROMO-study. J Occup Rehabil. 2007;17(3):370-82.

4. Herberts P, Kadefors R, Hogfors C, Sigholm G. Shoulder pain and heavy manual labor. Clin Orthop Relat Res. 1984;191:166-78.

5. Martimo KP, Shiri R, Miranda H, Ketola R, Varonen H, Viikari-Juntura E. Selfreported productivity loss among workers with upper extremity disorders. Scand J Work Environ Health. 2009;35(4):301-8.

6. Lambers Heerspink FO, Dorrestijn O, van Raay Jנ, Diercks RL. Specific patient-related prognostic factors for rotator cuff repair: a systematic review. J Shoulder Elbow Surg. 2014;23(7):1073-80.

7. Kemp KA, Sheps DM, Luciak-Corea C, Styles-Tripp F, Buckingham J, Beaupre LA. Systematic review of rotator cuff tears in workers' compensation patients. Occup Med (Lond). 2011;61(8):556-62.

8. Hawkins RJ, Misamore GW, Hobeika PE. Surgery for full-thickness rotator-cuff tears. J Bone Joint Surg Am. 1985;67(9):1349-55.

9. Misamore GW, Ziegler DW, Rushton III JL. Repair of the rotator cuff. A comparison of results in two populations of patients. J Bone Joint Surg Am. 1995;77(9):1335-9.

10. Shinners TJ, Noordsij PG, Orwin JF. Arthroscopically assisted mini-open rotator cuff repair. Arthroscopy. 2002;18(1):21-6.

11. Watson EM, Sonnabend DH. Outcome of rotator cuff repair. J Shoulder Elbow Surg. 2002;11(3):201-11.

12. Oh LS, Wolf BR, Hall MP, Levy BA, Marx RG. Indications for rotator cuff repair: a systematic review. Clin Orthop Relat Res. 2007;455:52-63.
13. Holtby R, Razmjou H. Impact of work-related compensation claims on surgical outcome of patients with rotator cuff related pathologies: A matched case-control study. J Shoulder Elbow Surg. 2010;19(3):452-60.

14. Koljonen P, Chong C, Yip D. Difference in outcome of shoulder surgery between workers' compensation and nonworkers' compensation populations. Int Orthop. 2009:33(2):315-20.

15. Nicholson GP. Arthroscopic acromioplasty: a comparison between workers' compensation and non-workers' compensation populations. J Bone Joint Surg Am. 2003;85-A(4):682-9.

16. Faber A, Hansen $\mathrm{K}$, Christensen $\mathrm{H}$. Muscle strength and aerobic capacity in a representative sample of employees with and without repetitive monotonous work. Int Arch Occup Environ Health. 2006;79(1):33-41.

17. Esmail S, Bhambhani Y, Brintnell S. Gender differences in work performance on the Baltimore Therapeutic Equipment work simulator. Am J Occup Ther. 1995:49(5):405-11.

18. Haward BM, Griffin MJ. Repeatability of grip strength and dexterity tests and the effects of age and gender. Int Arch Occup Environ Health. 2002;75(1-2):111-9.

19. Merrill A, Guzman K, Miller SL. Gender differences in glenoid anatomy: an anatomic study. Surg Radiol Anat. 2009:31(3):183-9.

20. Vafadar AK, Cote JN, Archambault PS. Sex differences in the shoulder joint position sense acuity: a cross-sectional study. BMC Musculoskelet Disord. 2015;16:273-015-0731-y.

21. Larsson B, Sogaard K, Rosendal L. Work related neck-shoulder pain: a review on magnitude, risk factors, biochemical characteristics, clinical picture and preventive interventions. Best Pract Res Clin Rheumatol. 2007;21(3):447-63.

22. Borkhoff CM, Hawker GA, Kreder HJ, Glazier RH, Mahomed NN, Wright JG. Influence of patients' gender on informed decision making regarding total knee arthroplasty. Arthritis Care Res (Hoboken). 2013:65(8):1281-90.

23. Borkhoff CM, Hawker GA, Kreder HJ, Glazier RH, Mahomed NN, Wright JG. The effect of patients' sex on physicians' recommendations for total knee arthroplasty. CMAJ. 2008;178(6):681-7

24. O'Connor Ml, Hooten EG. Breakout session: Gender disparities in knee osteoarthritis and TKA. Clin Orthop Relat Res. 2011;469(7):1883-5.

25. Razmjou H, Davis AM, Jaglal SB, Holtby R, Richards RR. Disability and satisfaction after rotator cuff decompression or repair: a sex and gender analysis. BMC Musculoskelet Disord. 2011:12:66-2474-12-66.

26. DeOrio JK, Cofield RH. Results of a second attempt at surgical repair of a failed initial rotator-cuff repair. J Bone Joint Surg Am. 1984;66(4):563-7.

27. Beaton DE, Wright JG, Katz JN, Upper Extremity Collaborative Group. Development of the QuickDASH: comparison of three item-reduction approaches. J Bone Joint Surg Am. 2005;87(5):1038-46.

28. Gallagher EJ, Liebman M, Bijur PE. Prospective validation of clinically important changes in pain severity measured on a visual analog scale. Ann Emerg Med. 2001;38(6):633-8.

29. Richards RR, An K, Bigliani LU, Friedman R, Gartsman GM, Gristina AG, lannotti JP, Mow VC, Sidles JA, Zuckerman JD. A standardized method for the assessment of shoulder function. J Shoulder Elbow Surg. 1994:3:347-52.

30. Ferreira-Valente MA, Pais-Ribeiro $J \mathrm{~L}$, Jensen MP. Validity of four pain intensity rating scales. Pain. 2011;152(10):2399-404.

31. Williamson A, Hoggart B. Pain: a review of three commonly used pain rating scales. J Clin Nurs. 2005:14(7):798-804.

32. Macdermid JC, Khadilkar L, Birmingham TB, Athwal GS. Validity of the QuickDASH in patients with shoulder-related disorders undergoing surgery. J Orthop Sports Phys Ther. 2015;45(1):25-36.

33. Mintken PE, Glynn P, Cleland JA. Psychometric properties of the shortened disabilities of the Arm, Shoulder, and Hand Questionnaire (QuickDASH) and Numeric Pain Rating Scale in patients with shoulder pain. J Shoulder Elbow Surg. 2009;18(6):920-6.

34. Michener LA, McClure PW, Sennett BJ. American Shoulder and Elbow Surgeons Standardized Shoulder Assessment Form, patient self-report section: reliability, validity, and responsiveness. J Shoulder Elbow Surg. 2002:11(6):587-94.

35. Ranalletta M, Rossi LA, Bongiovanni SL, Tanoira I, Elizondo CM, Maignon GD. Corticosteroid Injections Accelerate Pain Relief and Recovery of Function Compared With Oral NSAIDs in Patients With Adhesive Capsulitis: A Randomized Controlled Trial. Am J Sports Med. 2016:44(2):474-81.

36. Cohen J. Statistical power analysis for the behavioral sciences. In: Hillsdale NJ, editor. Lawrence Earlbaum Associates. 2nd ed. 1988.

37. Armstrong, $\mathrm{P}$, Armstrong $\mathrm{H}$. Thinking It Through: Women, Work and Caring in the New Millennium. Halifax: Maritime Centre of Excellence for Women's Health. 2001. Accessed on line August 4, 2016. http://www.dal.ca/content/ 
dam/dalhousie/pdf/ace-women-health/Healthy\%20Balance/ACEWH_hbrp_ thinking_it_through_women_work_caring_new_millennium.pdf

38. Tosi LL, Boyan BD, Boskey AL. Does sex matter in musculoskeletal health? The influence of sex and gender on musculoskeletal health. J Bone Joint Surg Am. 2005;87(7):1631-47.

39. Razmjou H, Davis AM, Jaglal SB, Holtby R, Richards RR. Cross-sectional analysis of baseline differences of candidates for rotator cuff surgery: a sex and gender perspective. BMC Musculoskelet Disord. 2009;10(1):26.

40. Briggs AM, Straker LM, Bear NL, Smith AJ. Neck/shoulder pain in adolescents is not related to the level or nature of self-reported physical activity or type of sedentary activity in an Australian pregnancy cohort. BMC Musculoskelet Disord. 2009;10:87-2474-10-87.

41. Rosati PM, Chopp JN, Dickerson CR. Investigating shoulder muscle loading and exerted forces during wall painting tasks: influence of gender, work height and paint tool design. Appl Ergon. 2014;45(4):1133-9.

42. Thinius M, Jakob M. Ergonomic workplace evaluation and epidemiology of musculoskeletal discomfort on German dairy farms. Work. 2014;49(1):25-32.

43. Davies JC, Manning DP, Kemp GJ, Frostick SP. The rising number of underfoot accidents after the menopause causes both fractures and nonfracture injuries. QJM. 2001;94(12):699-707.

44. Stevens JA, Sogolow ED. Gender differences for non-fatal unintentional fall related injuries among older adults. Inj Prev. 2005;11(2):115-9.

45. Razmjou H, Holtby $\mathrm{R}, \mathrm{Myhr} \mathrm{T}$. Gender differences in quality of life and extent of rotator cuff pathology. Arthroscopy. 2006;22(1):57-62.

46. White JJ, Titchener AG, Fakis A, Tambe AA, Hubbard RB, Clark DI. An epidemiological study of rotator cuff pathology using The Health Improvement Network database. Bone Joint J. 2014;96-B(3):350-3.

47. Polguj M, Rozniecki J, Sibinski M, Grzegorzewski A, Majos A, Topol M. The variable morphology of suprascapular nerve and vessels at suprascapular notch: a proposal for classification and its potential clinical implications. Knee Surg Sports Traumatol Arthrosc. 2015;23(5):1542-8.

48. Polguj M, Sibinski M, Grzegorzewski A, Grzelak P, Stefanczyk L, Topol M. Suprascapular Notch asymmetry: a study on 311 patients. Biomed Res Int. 2014;2014:196896.

49. Polguj M, Sibinski M, Grzegorzewski A, Waszczykowski M, Majos A, Topol M. Morphological and radiological study of ossified superior transverse scapular ligament as potential risk factor of suprascapular nerve entrapment. Biomed Res Int. 2014;2014:613601.

50. Zehetgruber H, Noske H, Lang T, Wurnig C. Suprascapular nerve entrapment. A meta-analysis. Int Orthop. 2002:26(6):339-43.

51. Gaudelli C, Hebert-Davies J, Balg F, Pelet S, Djahangiri A, Godbout V, Rouleau DM. The Impact of Superior Labral Anterior to Posterior Lesions on Functional Status in Shoulder Instability: A Multicenter Cohort Study. Orthop J Sports Med. 2014;2(10):2325967114554195.

52. Oliva F, Berardi AC, Misiti S, Maffulli N. Thyroid hormones and tendon: current views and future perspectives. Concise review. Muscles Ligaments Tendons J. 2013;3(3):201-3.

53. Oliva F, Piccirilli E, Bossa M, Via AG, Colombo A, Chillemi C, Gasparre G, Pellicciari L, Franceschetti E, Rugiero C, Scialdoni A, Vittadini F, Brancaccio P, Creta D, Buono AD, Garofalo R, Franceschi F, Frizziero A, Mahmoud A, Merolla G, Nicoletti S, Spoliti M, Osti L, Padulo J, Portinaro N, Tajana G, Castagna A, Foti C, Masiero S, Porcellini G, Tarantino U, Maffulli N. I.S.Mu.L.T - Rotator Cuff Tears Guidelines. Muscles Ligaments Tendons J. 2016;5(4):227-63.

54. Oliva F, Osti L, Padulo J, Maffulli N. Epidemiology of the rotator cuff tears: a new incidence related to thyroid disease. Muscles Ligaments Tendons J. 2014;4(3):309-14.

55. Oliva F, Misiti S, Maffulli N. Metabolic diseases and tendinopathies: the missing link. Muscles Ligaments Tendons J. 2014;4(3):273-4.

56. Yen PM. Physiological and molecular basis of thyroid hormone action. Physiol Rev. 2001;81(3):1097-142.

57. Ferry S, Hannaford P, Warskyj M, Lewis M, Croft P. Carpal tunnel syndrome: a nested case-control study of risk factors in women. Am J Epidemiol. 2000;151(6):566-74.

58. PURNELL DC, DALY DD, LIPSCOMB PR. Carpal-tunnel syndrome associated with myxedema. Arch Intern Med. 1961;108:751-6.

59. Zhu YS, Yen PM, Chin WW, Pfaff DW. Estrogen and thyroid hormone interaction on regulation of gene expression. Proc Natl Acad Sci U S A. 1996, 93(22):12587-92.

60. Hart DA, Archambault JM, Kydd A, Reno C, Frank CB, Herzog W. Gender and neurogenic variables in tendon biology and repetitive motion disorders. Clin Orthop Relat Res 1998;351:44-56.
61. Harvie P, Pollard TC, Carr AJ. Calcific tendinitis: natural history and association with endocrine disorders. J Shoulder Elbow Surg. 2007;16(2):169-73.

62. Oliva F, Via AG, Maffulli N. Physiopathology of intratendinous calcific deposition. BMC Med. 2012;10:95-7015-10-95.

63. Curry EJ, Matzkin EE, Dong Y, Higgins LD, Katz JN, Jain NB. Structural Characteristics Are Not Associated With Pain and Function in Rotator Cuff Tears: The ROW Cohort Study. Orthop J Sports Med. 2015;3(5): 2325967115584596.

64. Harris JD, Pedroza A, Jones GL, MOON (Multicenter Orthopedic Outcomes Network) Shoulder Group. Predictors of pain and function in patients with symptomatic, atraumatic full-thickness rotator cuff tears: a time-zero analysis of a prospective patient cohort enrolled in a structured physical therapy program. Am J Sports Med. 2012;40(2):359-66.

65. Rollman GB, Lautenbacher S. Sex differences in musculoskeletal pain. Clin J Pain. 2001;17(1):20-4.

66. Yunus MB. The role of gender in fibromyalgia syndrome. Curr Rheumatol Rep. 2001;3(2):128-34.

67. Mayer EA, Berman S, Chang L, Naliboff BD. Sex-based differences in gastrointestinal pain. Eur J Pain. 2004;8(5):451-63.

68. Chakrabarti S, Liu NJ, Zadina JE, Sharma T, Gintzler AR. Pleiotropic opioid regulation of spinal endomorphin 2 release and its adaptations to opioid withdrawal are sexually dimorphic. J Pharmacol Exp Ther. 2012;340(1):56-63.

69. Wiesenfeld-Hallin Z. Sex differences in pain perception. Gend Med. 2005:2(3):137-45

70. Turcotte M. Women and Health, Women in Canada: A Gender-based Statistical Report. Accessed on line Aug 4, 2016: http://www.statcan.gc.ca/ pub/89-503-x/2010001/article/11543-eng.pdf

71. Borkhoff CM, Hawker GA, Kreder HJ, Glazier RH, Mahomed NN, Wright JG. Patients' gender affected physicians' clinical decisions when presented with standardized patients but not for matching paper patients. J Clin Epidemiol. 2009;62(5):527-41.

72. Borkhoff CM, Hawker GA, Wright JG. Patient gender affects the referral and recommendation for total joint arthroplasty. Clin Orthop Relat Res. 2011; 469(7):1829-37.

73. Baxter NN. Equal for whom? Addressing disparities in the Canadian medical system must become a national priority. CMAJ. 2007;177(12):1522-3.

74. Katz JN, Wright EA, Guadagnoli E, Liang MH, Karlson EW, Cleary PD. Differences between men and women undergoing major orthopedic surgery for degenerative arthritis. Arthritis Rheum. 1994;37(5):687-94.

75. Rosenfeld AG, Lindauer A, Darney BG. Understanding treatment-seeking delay in women with acute myocardial infarction: descriptions of decisionmaking patterns. Am J Crit Care. 2005;14(4):285-93.

76. Takakuwa KM, Shofer FS, Hollander JE. The influence of race and gender on time to initial electrocardiogram for patients with chest pain. Acad Emerg Med. 2006;13(8):867-72.

77. Meryn S, Jadad AR. The future of men and their health. BMJ. 2001;323(7320): 1013-4.

78. Phillips SP. Defining and measuring gender: a social determinant of health whose time has come. Int J Equity Health. 2005;4:11.

\section{Submit your next manuscript to BioMed Central and we will help you at every step:}

- We accept pre-submission inquiries

- Our selector tool helps you to find the most relevant journal

- We provide round the clock customer support

- Convenient online submission

- Thorough peer review

- Inclusion in PubMed and all major indexing services

- Maximum visibility for your research

Submit your manuscript at www.biomedcentral.com/submit
Biomed Central 